Review Article

\title{
Classification and applying pharmacovigilance principles to study adverse drug reaction and its management
}

\author{
Srihitha Pendota*, Sre Akshaya Kalyani Surabhineni, Abhinay Sharma Katnapally, \\ Dharanija Porandla, Sandeep Kumar Beemreddy
}

Department of Clinical

Pharmacy, Vaageswari College of Pharmacy, Thimmapur, Karimnagar 505001, Telangana, India

Received: 04 September 2017

Revised: 03 October 2017

Accepted: 07 October 2017

*Correspondence to:

Dr. Srihitha Pendota,

Email: pendotasrihitha95@

gmail.com

Copyright: (C) the author(s), publisher and licensee Medip Academy. This is an openaccess article distributed under the terms of the Creative Commons Attribution NonCommercial License, which permits unrestricted noncommercial use, distribution, and reproduction in any medium, provided the original work is properly cited.

\begin{abstract}
Adverse drug reaction (ADR) is an unwanted, undesirable effect of medication resulting in mild to severe effect on the patient. This review explains definitions of ADR and it differentiation with adverse drug event, medication error. ADRs may cause increased length of stay or initial reason for admission and are major cause of morbidity and mortality worldwide. Risk factors for ADR occurrence include age, gender, patients with multiple diseases and multiple drug therapy (polypharmacy). ADRs are classified into different types based on the mechanism and onset of reaction. The causal relation between suspected drug and reaction can be assessed by using causality assessment scales. The severity and preventability of ADR can be assessed by severity assessment scale and preventability scale respectively. Clinical Pharmacists play an important role in monitoring and management of ADRs.
\end{abstract}

Keywords: Adverse drug reaction, Causality, Clinical pharmacist, Hartwig severity assessment scale, Naranjo's scale, Pharmacovigilance, Preventability scale, Severity scale, Schumock and Thornton preventability scale, WHO scale

\section{INTRODUCTION}

The world health organisation (WHO) defines an ADR as "any response to a drug which is noxious and unintended, and which occurs at doses normally used in man for prophylaxis, diagnosis or therapy of a disease, or for the modification of physiological function."

This definition excludes overdose (either accidental or intentional), drug abuse, failure of treatment, and drug administration errors. ${ }^{1}$
American Society of Hospital Pharmacists (ASHP) defines a significant ADR as any unexpected, unintended, undesired, or excessive response to a drug that:

- Requires discontinuing the drug (therapeutic or diagnostic),

- Requires changing the drug therapy,

- Requires modifying the dose (except for minor dosage adjustments),

- Necessitates admission to a hospital,

- Prolongs stay in a health care facility,

- Necessitates supportive treatment, 
- Significantly complicates diagnosis,

- Negatively affects prognosis, or results in temporary or permanent harm, disability or death.

- This definition includes allergic reaction and an idiosyncratic reaction. ${ }^{2}$

\section{FDA (Food and Drug administration)}

FDA termed ADR or serious drug event as an event relating to drugs or devices, as one in which the patient outcome is death, life-threatening, hospitalization, disability, birth defects (congenital abnormalities), or required intervention to prevent permanent impairment or damage. ${ }^{3}$

\section{Adverse Drug Event (ADE)}

Any untoward occurrence that may present during treatment with a pharmaceutical product but that does not necessarily have a causal relation to the treatment (WHO). Injuries caused by medical interventions related to a drug. ADEs may result from medication errors or from ADRs in which there was no error. ${ }^{4}$

\section{Medication error}

The United States National Coordinating Council for Medication Error Reporting and Prevention (US NCC MERP) defines a medication error as "any preventable event that may cause or lead to inappropriate medication use or patient harm while the medication is in the control of the health care professional, patient, or consumer. Such events may be related to professional practice, health care products, procedures, and systems, including prescribing, order communication, product labeling, packaging, and nomenclature, compounding, dispensing, distribution, administration, education, monitoring, and use". ${ }^{5}$

\section{EPIDEMIOLOGY}

ADRS are alleged to be the 4 th leading cause of death. ${ }^{6}$ $35 \%$ of hospitalized patients experience an ADR during their hospital stays. ${ }^{7}$ The overall incidence of serious ADRs is $6.7 \%$ and of fatal ADRs is $0.32 \%$ in hospitalized patients, making these reactions between the fourth and sixth leading cause of death, respectively. ${ }^{8}$

\section{Risk factors}

Age of Patient: It is estimated that ADRs are dependent on age of the patient. Geriatric patients consume more medicines than other age groups due to co-morbidities and complexity of medical problems. ADRs may be as a result of drug-drug interactions, in geriatric patients due to the modification of metabolic enzymes. Elder patients are more prone to Type-A reactions than Type-B..$^{9-11}$ In children, the incidence of ADRs is more in pediatrics age group than adult since metabolic enzymes are not fully developed. So, the accumulation of drug might be a causative factor for the development of ADRs. In addition, the body fats are low, creating problematic situation for lipid soluble drugs..$^{12,13}$

\section{Gender}

The biological differences of males and females affect the action of many drugs. The anatomical and physiological differences are body weight, body composition, gastrointestinal tract factors, liver metabolism, and renal function. Women are more susceptible to develop ADR, since women in comparison to men have lower body weight and organ size, more body fat, different gastric motility and lower glomerular filtration rate. These differences can affect the way the body deals with drugs by altering the pharmacokinetics and pharmacodynamics of the drugs including drug absorption, distribution, metabolism and elimination. A study of sex differences in ADRs to antiretroviral drugs indicates potential sex differences in the frequency and severity of ADRs to antiretroviral drugs. ${ }^{14}$ Hepatic enzyme CYP3A4 is more active in females than males which lead to different effects on drug metabolism. ${ }^{15}$

Hepatic and renal impairment patients: Patients with liver disorders, renal impairment is with an increased risk of developing ADRs due to alteration in pharmacokinetics i.e., drug metabolism and excretion respectively. Lower doses or reduced dosing frequency is often recommended, due to altered PKs in hepatic impaired patients. Drugs that can precipitate renal failure, gastrointestinal bleeding and encephalopathy should be identified and avoided. ${ }^{16}$

\section{Drug dose and frequency}

Drug dosing affects the development of ADRs in many ways; e.g. some drugs need to be given in the morning and others in the evening, some at bedtime. Taking bisphosphonates at bed time may lead to esophagitis, the antiplatelet effect of aspirin when taken in the evening is more potent than in the morning. ${ }^{17}$

\section{Drug characteristics}

Some drugs are highly toxic in nature and patients treated with these agents are at an increased risk of ADRs. Example: Patients treated with anticancer drugs are commonly prone to nausea and vomiting. ${ }^{18}$ Drugs with narrow therapeutic index result in toxicity due to a slight increase in the serum drug concentration Example: digoxin, gentamicin. ${ }^{19}$

\section{Polypharmacy}

Polypharmacy is defined according to the WHO criteria as the, "concurrent use of five or more different prescription medication". The amount of risk associated with multiple drug therapy increases with the increased number of drugs administered. Patients with multiple drug therapy are more prone to develop an ADR due to alteration of drug effect through an interaction mechanism, or by synergistic effect. 
The overall occurrence of ADRs due to polypharmacy was $70 \% .{ }^{20}$

\section{CLASSIFICATION OF ADRs}

Rawlins and Thompson classified adverse drug reactions into two types. ${ }^{21}$ They are:

Type A

These reactions are dose dependent, predictable from the known pharmacology of the drug

\section{Type B}

These reactions are dose independent and are unpredictable.

Wills and Brown classified adverse drug reactions into nine different types. ${ }^{22}$ They are:

\section{Type A: Augmented reactions}

These reactions are dose related actions, which could have been predicted based on the mode of action and pharmacology of a drug or excipient. These reactions may improve partially or completely when the dose is reduced or offending drug is withdrawn. Example - bradycardia associated with $\beta$-blockers.

\section{Type B: Bugs reactions}

These reactions rely upon promoting the growth of certain microorganisms, since the direct and principal pharmacological action is on the bodies of microorganism rather than on the human body. These are pharmacologically predictable events. Example - Broad spectrum antibiotics causing oral thrush and over use of one agent stimulating the development of resistance among a specific species of microorganism rendering further use of the agent ineffective.

\section{Type C: Chemical reactions}

These reactions depend upon the chemical nature of a drug or excipient rather than pharmacological properties. These are not pharmacologically predictable, but may be seen based on the knowledge of physicochemical characteristics of the drug. The severity of a type C reaction is more related to offending substance than dose. Example - Gastrointestinal mucosa damage caused by local irritant action.

\section{Type D: Delivery reactions}

These reactions do not depend upon the chemical or pharmacological properties of the constituents of the preparation, but occur because of the physical nature of the formulation and/or the method of administration. These reactions are heterogeneous because when the methods of delivery vary the specific nature of the adverse reactions must also vary and if the method of delivery is changed, the adverse reaction will stop to occur. Example - Particles in injections causing thrombosis or blood vessel occlusion.

\section{Type E: Exit reactions}

These reactions are pharmacologically predictable and known as withdrawal reactions. It occurs after stopping the administration of the medicine or when the dose is suddenly reduced. The condition of the patient improves when the drug therapy is reintroduced. Example Withdrawal seizure when anticonvulsants like Phenytoin is withdrawn.

\section{Type F: Familial reaction}

These reactions occur only in susceptible individuals with genetically determined, inherited metabolic disorders. Some of the more common familial disorders include phenyl ketonuria, glucose 6-phosphate dehydrogenase deficiency (G6PD); esterase inhibitor deficiency, porphyria and sickle cell anaemia. Example - hemolytic anemia with primaquine in G6PD deficient individuals.

\section{Type G: Genotoxicity reactions}

These reactions can cause irreversible genetic damage. A number of drugs can produce genetic damage in humans, some are potentially carcinogenic or genotoxic. Example teratogenic agent like thalidomide causes genetic damage to the developing fetus.

\section{Type H: Hypersensitivity reactions}

They are not pharmacologically predictable, and neither are they dose related (although very small doses can sometimes be used for desensitization) caused by allergy or hypersensitivity. These involve activation of an immune response. Accordingly, reducing the dose does not usually lead to amelioration of symptoms; the drug must be stopped. Factors associated with an increased risk for hypersensitivity drug reactions include use of beta blockers or asthma, systemic lupus erythematosus. ${ }^{23,24}$ Example - hypersensitivity mediated blood dyscrasias.

\section{Type U: Unclassified reactions}

This includes reactions in which the mechanism is unclear. This may necessitate the introduction of new adverse reaction categories in the future. Examples - nausea and vomiting after a gaseous general anesthetic.

\section{Classification of ADR based on its severity: ${ }^{25}$}

The severity of ADR can be categorized into 4 which are mild, moderate, severe and lethal. 
1. Mild adverse reactions are those in which no antidote or treatment is required and also hospitalization is not required. Example - constipation caused by opioids.

2. Moderate adverse reaction requires treatment where doses may be modified, but there is no necessity for the therapy to be discontinued. Also, hospitalization may be prolonged for the patient with moderate adverse reaction. Example - Venous thrombosis caused by hormonal contraceptive falls under this category.

3. Severe adverse drug reaction, is potentially life threatening. It is recommended to discontinue the drug therapy and special treatment is required. Example- angioedema caused by enalapril.

4. Lethal adverse drug reaction that may bring about death either directly or indirectly. ExampleHemorrhage due to anticoagulants.

Table 1: Naranjo's causality assessment scale.

\begin{tabular}{|c|c|c|c|}
\hline Questions & Yes & No & Don't know \\
\hline 1. Are there previous conclusive reports on this reaction? & +1 & 0 & 0 \\
\hline 2. Did the adverse event appear after the suspected drug was administered? & +2 & -1 & 0 \\
\hline $\begin{array}{l}\text { 3. Did the adverse reaction improve when the drug was discontinued or a specific } \\
\text { antagonist was administered? }\end{array}$ & +1 & 0 & 0 \\
\hline 4. Did the adverse event reappear when the drug was re-administered? & +2 & -2 & 0 \\
\hline $\begin{array}{l}\text { 5. Are there alternative causes (other than the drug) that could on their own have caused } \\
\text { the reaction? }\end{array}$ & -1 & +2 & 0 \\
\hline 6. Did the reaction reappear when a placebo was given? & -1 & +1 & 0 \\
\hline 7. Was the drug detected in blood (or other fluids) in concentrations known to be toxic? & +1 & 0 & 0 \\
\hline $\begin{array}{l}\text { 8. Was the reaction more severe when the dose was increased or less severe when the dose } \\
\text { was decreased? }\end{array}$ & +1 & 0 & 0 \\
\hline $\begin{array}{l}\text { 9. Did the patient have a similar reaction to the same or similar drugs in any previous } \\
\text { exposure? }\end{array}$ & +1 & 0 & 0 \\
\hline 10. Was the adverse event confirmed by any objective evidence? & +1 & 0 & 0 \\
\hline
\end{tabular}

Table 2: Interpretation of scores.

\begin{tabular}{|c|c|c|}
\hline Score & Causality & Interpretation of Scores \\
\hline $\begin{array}{l}\text { Total Score } \\
\geq 9\end{array}$ & Definite & $\begin{array}{l}\text { The reaction (1) followed a reasonable temporal sequence after a drug or in which a } \\
\text { toxic drug level had been established in body fluids or tissues, (2) followed a recognized } \\
\text { response to the suspected drug, and (3) was confirmed by improvement on withdrawing } \\
\text { the drug and reappeared on reexposure. }\end{array}$ \\
\hline $\begin{array}{l}\text { Total Score } \\
5 \text { to } 8\end{array}$ & Probable & $\begin{array}{l}\text { The reaction (1) followed a reasonable temporal sequence after a drug, (2) followed a } \\
\text { recognized response to the suspected drug, ( } 3 \text { ) was confirmed by withdrawal but not by } \\
\text { exposure to the drug, and (4) could not be reasonably explained by the known } \\
\text { characteristics of the patient's clinical state. }\end{array}$ \\
\hline $\begin{array}{l}\text { Total Score } \\
1 \text { to } 4\end{array}$ & Possible & $\begin{array}{l}\text { The reaction (1) followed a temporal sequence after a drug, (2) possibly followed a } \\
\text { recognized pattern to the suspected drug, and ( } 3 \text { ) could be explained by characteristics of } \\
\text { the patient's disease. }\end{array}$ \\
\hline Total Score $\leq 0$ & Doubtful & The reaction was likely related to factors other than a drug. \\
\hline
\end{tabular}

\section{CAUSALITY ASSESSMENT}

Causality is the extent of relationship between a suspected reaction and a suspected drug. Different scales used for assessing causality are Naranjo's scale, and WHO UMC scale. $^{26,27}$

\section{Naranjo's causality assessment scale}

Table 1 and 2 represents Naranjo's scale and interpretation of scores.

\section{WHO-UMC causality assessment scale}

WHO (World Health Organisation) designed a causality scale by collaborating with Uppsala monitoring centre. They divided the scale into different categories based on assessment criteria. Table 3 explains the scale:

\section{Severity assessment scale}

The severity of ADRs is assessed by using the Hartwig scale. The scale includes different levels each of which 
explains the severity of reaction. The ADR reaction is categorized into mild, moderate or severe. ${ }^{28}$

Table 3: WHO-UMC causality assessment scale.

\begin{tabular}{|c|c|}
\hline $\begin{array}{l}\text { Causality } \\
\text { term }\end{array}$ & Assessment criteria \\
\hline Certain & $\begin{array}{l}\text { - Event or laboratory test } \\
\text { abnormality, with plausible time } \\
\text { relationship to drug intake } \\
\text { - Cannot be explained by disease or } \\
\text { other drugs } \\
\text { - Response to withdrawal plausible } \\
\text { (pharmacologically, pathologically) } \\
\text { - Event definitive pharmacologically } \\
\text { or phenomenologically (i.e. an } \\
\text { objective and specific medical } \\
\text { disorder or a recognised } \\
\text { pharmacological phenomenon) } \\
\text { - Rechallenge satisfactory, if } \\
\text { necessary }\end{array}$ \\
\hline $\begin{array}{l}\text { Probable / } \\
\text { Likely }\end{array}$ & $\begin{array}{l}\text { - Event or laboratory test } \\
\text { abnormality, with reasonable time } \\
\text { relationship to drug intake } \\
\text { - Unlikely to be attributed to disease } \\
\text { or other drugs } \\
\text { - Response to withdrawal clinically } \\
\text { reasonable } \\
\text { - Rechallenge not required }\end{array}$ \\
\hline Possible & $\begin{array}{l}\text { - Event or laboratory test } \\
\text { abnormality, with reasonable time } \\
\text { relationship to drug intake } \\
\text { - Could also be explained by disease } \\
\text { or other drugs } \\
\text { - Information on drug withdrawal } \\
\text { may be lacking or unclear }\end{array}$ \\
\hline Unlikely & $\begin{array}{l}\text { - Event or laboratory test } \\
\text { abnormality, with a time to drug } \\
\text { intake that makes a relationship } \\
\text { improbable (but not impossible) } \\
\text { - Disease or other drugs provide } \\
\text { plausible explanations }\end{array}$ \\
\hline $\begin{array}{l}\text { Conditional / } \\
\text { Unclassified }\end{array}$ & $\begin{array}{l}\text { - Event or laboratory test abnormality } \\
\text { - More data for proper assessment } \\
\text { needed, or } \\
\text { - Additional data under examination }\end{array}$ \\
\hline $\begin{array}{l}\text { Unassessable } \\
\text { / Unclassifiable }\end{array}$ & $\begin{array}{l}\text { - Report suggesting an adverse } \\
\text { reaction } \\
\text { - Cannot be judged because } \\
\text { information is insufficient or } \\
\text { contradictory } \\
\text { - Data cannot be supplemented or } \\
\text { verified }\end{array}$ \\
\hline
\end{tabular}

\section{Preventability scale}

Schumock and Thornton preventability scale: This scale determines whether the ADR is whether definitely preventable, probably preventable or not preventable.
Table 4: Hartwig severity assessment scale.

\begin{tabular}{|c|c|}
\hline Level 1 & $\begin{array}{l}\text { An ADR occurred but required no change } \\
\text { in treatment with the suspected drug }\end{array}$ \\
\hline Level 2 & $\begin{array}{l}\text { The ADR required that treatment with the } \\
\text { suspected drug be held, discontinued, or } \\
\text { otherwise changed. No antidote or other } \\
\text { treatment requirement was required. No } \\
\text { increase in length of stay (LOS). }\end{array}$ \\
\hline Level 3 & $\begin{array}{l}\text { The ADR required that treatment with the } \\
\text { suspected drug be held, discontinued, or } \\
\text { otherwise changed. AND/OR an Antidote or } \\
\text { other treatment was required. No increase in } \\
\text { length of stay (LOS). }\end{array}$ \\
\hline Level 4 & $\begin{array}{l}\text { Any level } 3 \text { ADR which increases length of } \\
\text { stay by at least } 1 \text { day or The ADR was the } \\
\text { reason for the admission. }\end{array}$ \\
\hline Level 5 & $\begin{array}{l}\text { Any level } 4 \text { ADR which requires intensive } \\
\text { medical care. }\end{array}$ \\
\hline Level 6 & $\begin{array}{l}\text { The adverse reaction caused permanent } \\
\text { harm to the patient. }\end{array}$ \\
\hline Level 7 & $\begin{array}{l}\text { The adverse reaction either directly or } \\
\text { indirectly led to the death of the patient. }\end{array}$ \\
\hline
\end{tabular}

Table 5: Schumock and Thornton preventability scale.

\section{Definitely Preventable}

1. Was there a history of allergy or previous reactions to the drug?

2. Was the drug involved inappropriate for the patient's clinical condition?

3. Was the dose, route or frequency of administration inappropriate for the patient's age, weight or disease state?

4. Was a toxic serum drug concentration (or laboratory monitoring test) documented?

5. Was there a known treatment for the Adverse Drug Reaction?

Probably Preventable

6. Was required Therapeutic drug monitoring or other necessary laboratory tests not performed?

7. Was a drug interaction involved in the ADR?

8. Was poor compliance involved in the ADR?

9. Were preventative measures not prescribed or administered to the patient?

Not preventable

If all above criteria not fulfilled

\section{MONITORING OF ADRs}

The discovery of an adverse drug effect is a step-wise process consisting of following different steps:

- Hypothesis generation

- Hypothesis strengthening and preliminary assessment of the available data

- $\quad$ Signal testing, evaluation and explanation 
A signal is broadly defined as a set of data constituting a hypothesis that is relevant to the rational and safe use of drugs in humans. Such data are usually clinical pharmacological, pathological or epidemiological in nature. Signals in pharmacovigilance are usually derived from observations in individual patients or from experimental studies and have a qualitative and a quantitative dimension sources of signals.

- Observations in patients (qualitative signals)

- Spontaneous monitoring

- Anecdotal literature reporting

- Intensive hospital monitoring

- Prescription event monitoring

- Follow-up studies

- Monitored release programmes

- Observations in populations (quantitative signals)

- Large data sources on morbidity and drug use

- Case-control studies

- Case-control surveillance

- Follow-up studies

- Prescription event monitoring

- Intensive hospital monitoring

- Large spontaneous reporting systems (eg : WHO, FDA)

- $\quad$ Experimental findings

- Clinical trials

- In vitro experiments

- Animal toxicology ${ }^{29}$

\section{Management of ADRs}

ADR reaction can be determined by the scales. By the reaction type determined managing can be done in different manners.

- Discontinuation of the offending drug if the reaction is severe

- $\quad$ Addition of an alternate drug; replace the offending drug with another

- Continuing the same treatment and treat symptoms of reaction if necessary

- Reducing dose

- Discontinuation non-essential medications

- 6. Administer appropriate treatment

\section{Role of pharmacist in the management of ADRs}

- Monitoring the patients who are at greater risk of developing ADRs

- Monitoring the patients who are prescribed with drugs highly susceptible to cause ADRs

- Assessing and documenting the patients previous allergic status
- Assessing the patients drug therapy for its appropriateness

- Assessing possible drug interactions for patients on multiple therapies

- Assisting health care professionals in detection and assessment of ADRs

- $\quad$ Encouraging health care professionals in reporting ADRs

- Documentation of suspected reported reactions for future reference

- Follow-up of patients to assess the outcome of the reaction and management

- Obtaining feedback about the reported reaction

- Educating health care professionals about the importance of reporting of an ADR

- $\quad$ Educating patients

- Creating awareness about ADRs amongst health care professionals, patients and public

- $\quad$ Preparation and utilization of promotional materials

- Communication with other health care professionals such as nurses and community pharmacists

- Presentation of reports in meetings and conference

- Conducting workshops, conferences, seminars on ADRs for health care professionals

- Dissemination of signals generated through publication of reports in bulletins or journals. ${ }^{30}$

\section{Reporting of ADRs}

Reporting of an ADR is an important step. ADR reporting brings awareness in health care professionals, to the pharmaceutical companies, to the researchers about post marketing surveillance, to the drug users (patients), students etc.

Components of an ADR Report:

- $\quad$ Product name and manufacturer

- $\quad$ Patient demographics: age, gender

- Description of adverse event and outcome

- Date of onset of reaction occurred

- Seriousness of the reaction: Death, Life threatening, Hospitalization-initial or prolonged, Disability, Congenital anomaly, required intervention to prevent permanent impairment / damage, Others

- $\quad$ Drug start and stop dates/times

- Dose, frequency, and route of administration

- Relevant lab test results or other objective evidence

- De-challenge and re-challenge information

- Confounding variables

Different forms of ADR reporting include:

The standard reporting form is different for different countries, for India the standard form is CDSCO form:

- Central Drugs standard for control of organization (CDSCO) ADR reporting form in India. 
- $\quad$ Yellow card reporting form for UK by Medicines and Healthcare products Regulatory Agency (MHRA).

- MedWatch form is an ADR reporting form for US by food and drug administration (FDA).

- Blue Card ADR reporting form for Australia by therapeutic goods administration (TGA).

\section{CONCLUSION}

ADR is one of the primary cause leading to morbidity and mortality in the world. Health care professionals particularly in India must be aware of differentiating an ADR with the disease. ADR reporting should be made aware to everyone by conducting seminars and workshops. Active participation of clinical pharmacists and other health care professionals in reporting ADRs decreases the occurrence and brings an ease in management.

\section{Funding: No funding sources}

Conflict of interest: None declared

Ethical approval: Not required

\section{REFERENCES}

1. Parthasarathi G, Sten O. Adverse drug reactions in: Parthasarathi G, Karin Nyfort-Hansen, Milap C Nahata, editors. A Textbook of Clinical Pharmacy Practice: Essential concepts and skills, published by Orient Longman Private Limited, Inc; 2004:84-102.

2. American Society of Hospital Pharmacists. ASHP assistance bulletin on hospital drug distribution and control. Am J Hosp Pharm. 1980;37:1097-103.

3. Kessler DA. Introducing Med Watch, using FDA for 3500. A New Approach to Reporting Medication and Device Adverse Effects and Product problems. JAMA.1993;269:2765-68.

4. Bates DW, Boyle DL, Vander Vliet MB. Relationship between medication errors and adverse drug events. J Gen Intern Med. 1995;10:199-205.

5. National Coordinating Council for Medication Error Reporting and Prevention. What is a medication error? New York, NY: National Coordinating Council for Medication Error Reporting and Prevention; 2015. Available at: http://www.nccmerp.org/aboutmedication-errors, accessed 19 September 2016).

6. BA B. Development and regulation of drugs. In: Katzung BG. Ed. Basic and clinical pharmacology. $10^{\text {th }}$ Ed. lange Medical Books/ McGraw-Hill, New York; 2007.

7. Murphy BM, Frigo LC. Development, implementation, and results of a successful multidisciplinary adverse drug reaction reporting program in a university teaching hospital. Hosp Pharm. 1993;28:1199-204,240.

8. Lazarou J, Pomeranz BH, Corey PN. Incidence of adverse drug reactions in hospitalized patients-a metaanalysis of prospective studies. JAMA. 1998;279:1200-5
9. Barry PJ, Gallagher P, Ryan C. Inappropriate prescribing in geriatric patients. Curr Psychiatry Rep. 2008;10(1):37-43.

10. Bowman L, Carlstedt BC, Hancock EF, Black CD. Adverse drug reaction (ADR) occurrence and evaluation in elderly inpatients. Pharmacoepidemiol Drug Saf. 1996;5(1):9-18.

11. Leach S, Roy SS. Adverse drug reactions: an investigation on an acute geriatric ward. Age Ageing. 1986;15(4):241-6.

12. Alomar MJ. Factors affecting the development of adverse drug reactions (Review article). Saudi Pharm J 2013;22(2):83-94.

13. Ibáñez L, López-Bermejo A, Díaz M, Marcos MV, Casano P, de Zegher F. Abdominal fat partitioning and highmolecular-weight adiponectin in short children born small for gestational age. J Clin Endocrinol Metab. 2009;94(3):1049-52.

14. Ofotokun I, Pomeroy C. Sex differences in adverse reactions to antiretroviral drugs. Top. HIV Med. 2003;11(2):55-9.

15. El-Eraky H, Thomas SHL. Effects of sex on the pharmacokinetic and pharmacodynamic properties of quinidine. Br. J. Clin. Pharmacol. 2003;56:198-204.

16. Lewis JH, Stine JG. Review article. Review article: prescribing medications in patients with cirrhosis. Aliment Pharmacol Ther. 2013;37:1132-56.

17. Hermida RC, Ayala DE, Calvo C, Lo'pez JE. Aspirin administered at bedtime, but not on awakening has an effect on ambulatory blood pressure in hypertensive patients. J. Am. Coll. Cardiol. 2005;46(6):975-83.

18. Warr DG. Chemotherapy- and cancer-related nausea and vomiting. Current oncology. 2008;15(1):S4-9.

19. Blix HS, Viktil KK, Moger TA, Reikvam A. Drugs with narrow therapeutic index as indicators in the risk management of hospitalised patients. Pharmacy practice. 2010;8(1):50-5.

20. Ahmed B, Nanji K, Mujeeb R, Patel MJ. Effects of polypharmacy on adverse drug reactions among geriatric outpatients at a tertiary care hospital in Karachi: a prospective cohort study. PloS one. 2014 Nov 17;9(11):e112133.

21. Rawlins MD, Thompson JW. Pathogenesis of adverse drug reactions. In: Davies DM, ed. Textbook of adverse drug reactions. Oxford: Oxford University Press; 1977:10.

22. Arulmani R, Rajendran SD, Suresh B. Adverse drug reaction monitoring in a secondary care hospital in South India. British J of Clin Pha. 2007;65(2):210-16.

23. Lang DM, Alpern MB, Visintainer PF, Smith ST. Increased risk for anaphylactoid reaction from contrast media in patients on beta-adrenergic blockers or with asthma. Ann Intern Med. 1991;115:270-6.

24. Petri M, Allbritton J. Antibiotic allergy in systemic lupus erythematosus: a case-control study. J Rheumatol. 1992;19:265-9.

25. Gholami K, Gloria S. Factors Associated with Preventability, Predictability, and Severity of Adverse Drug Reactions. Annals of Pharmacotherapy. 1999;33(2):236-40. 
26. Naranjo CA, Busto U, Sellers EM, Sandor P, Ruiz I, Roberts EA, et al. A method for estimating the probability of adverse drug reactions. Clin Pharmacol Ther. 1981;30(2):239-45.

27. World Health Organization (WHO). The Use of the WHO-UMC System for Standardized Case Causality Assessment. Geneva: WHO; 2014.

28. Hartwig SC, Siegel J, Schneider PJ. Preventability and severity assessment in reporting adverse drug reactions. Am J Hosp Pharm. 1992;49:2229-32.

29. Goyal RK, Bhatt PA, Burande MD. Adverse drug reactions and Pharmacovigilance: Elements of Clinical Pharmacy: published by S. B Shah, $3^{\text {rd }}$ Ed: 2006-2005:126-127.
30. Kessler DA, Natanblut S, Kennedy D, Lazar E, Rheinstein P, Anello C, et al. Introducing MEDWatch: a new approach to reporting medication and device adverse effects and product problems. Jama. 1993 Jun $2 ; 269(21): 2765-8$.

Cite this article as: Pendota S, Surabhineni SAK, Katnapally AS, Porandla D, BeemreddySK.

Classification and applying pharmacovigilance principles to study adverse drug reaction and its management. Int $\mathrm{J}$ Basic Clin Pharmacol 2017;6:2537-44. 